\title{
Artefatos educacionais com memória cinética Topobo: uma abordagem para o currículo dos anos iniciais
}

\author{
Mateus Madail Santin, João Alberto da Silva, Silvia Silva da Costa Botelho \\ Programa de Pós-graduação em Educação em Ciências: Química da Vida e Saúde - \\ Universidade Federal do Rio Grande - FURG \\ Avenida Itália Km 8 - Campus Carreiros CEP: 96201-900 Rio Grande - RS - Brasil
}

\{mateus.santin, joaosilva, silviacb\}@furg.br

\begin{abstract}
Resumo Este artigo apresenta o lúdico como uma forma de trabalhar conteúdos na escola, mostrando de forma introdutória a importância desta atividade. Após é apresentado o kit Topobo, uma ferramenta de uso pedagógico desenvolvido no laboratório de mídias do MIT (Massachusetts Institute of Technology) o qual é comercializado em caixas com diferentes quantidades de peças, onde o professor pode explorar conteúdos de forma lúdica. A partir disto, é mostrada uma metodologia para auxiliar o professor a trabalhar com robótica educacional em sala de aula, e por fim conclui com algumas percepções do uso de um kit Topobo comercial de 100 peças.
\end{abstract}

Palavras Chave: "Topobo", "Kits Robóticos", "Educação básica".

\section{Artifacts educational Topobo kinetic memory: a approach to curriculum of the early years}

\begin{abstract}
This paper presents the ludic as a form of content in school work, showing in an introductory way the importance of this activity. After the kit is presented Topobo, a tool developed in the pedagogical use of the MIT Media Lab (MIT) which is sold in boxes with different quantities of parts, where the teacher can explore content in a ludic. From this, there is shown a methodology to help the teacher to work with educational robotics in the classroom, and finally concludes with some perceptions of using a commercial kit Topobo 100 pieces.
\end{abstract}

Key words: "Topobo", "Robotics Kits", "Basic Education"

\section{Atividades lúdicas e o processo de aprendizagem}

Nesta seção será apresentado o lúdico como uma forma de se trabalhar conteúdos na escola, mostrando de forma introdutória a importância desta atividade nas séries iniciais.

A introdução do brincar no currículo estimula o desenvolvimento físico, cognitivo, criativo, social e a linguagem da criança pequena (Saracho, 1991). Nas relações do cotidiano dos alunos, em particular os das séries iniciais, o lúdico faz parte do cotidiano, atividades que referencie o brincar são melhores aceitas por eles. 
O professor como parte do processo de aprendizagem precisa de alguma forma despertar o interesse de seus alunos para que eles passem a ter um conhecimento científico das atividades lúdicas as quais eles estão comumente habituados a realizar. Para Vygotsky (1987), a aprendizagem e o desenvolvimento estão estritamente relacionados, sendo que as crianças se inter-relacionam com o meio objeto e social, internalizando o conhecimento advindo de um processo de construção. Segundo Piaget (1971), o brincar implica uma dimensão evolutiva com as crianças de diferentes idades, apresentando características específicas, apresentando com formas diferenciadas de brincar.

Entretanto, na escola a criança precisa permanecer durante muitas horas em carteiras nada adequadas. Em geral as salas são desconfortáveis e as crianças precisam estar regradas a horários, e, impossibilitadas de moverem-se livremente. A disciplina escolar faz com que muitas vezes a criança apresente certa resistência em ir à escola. $\mathrm{O}$ fato não está apenas no total desagrado pelo ambiente ou pela nova forma de vida, mas sim, por não encontrar canalização para as suas atividades preferidas (Bittencourt e Ferreira, 2002).

A escola que insere atividade lúdica, como um meio favorecedor do processo de autonomia da aprendizagem, tem no professor, um papel importante, o de intervir na atividade de forma a contribuir com esse processo. Seu papel como proponente de atividades lúdicas e mediador delas é na administração do tempo entre as ações e proporcionar com as atividades lúdicas um processo de construção do conhecimento.

\section{Topobo uma ferramenta lúdica para o ensino}

Nesta seção é apresentado o kit Topobo, uma ferramenta que pode ser explorada pelo professor para trabalhar os conteúdos de forma lúdica, desenvolvido no laboratório de mídias do MIT por Hayes Raffle e Amanda Parkes.

O nome Topobo é derivado das palavras topology, botanical, e robot ,o qual se constitui em um sistema de modelagem em 3D que permite ser configurado de diferentes formas e programado para fisicamente se mover. A capacidade de representação 3D do Topobo permite que o aluno contextualize e crie objetos relacionados com a sua percepção. Na figura 1 são visualizadas as peças passivas e a peça ativa.

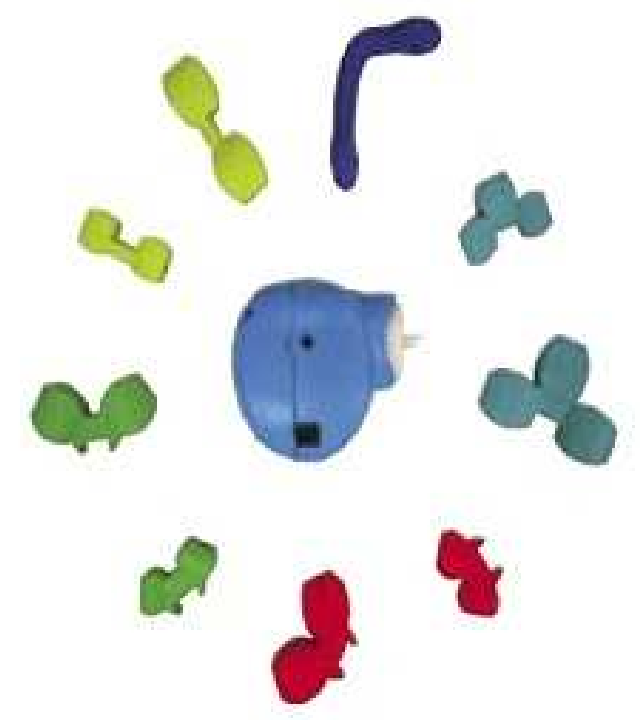

Figura 1. Conjunto de primitivas ativas e passivas que formam o Topobo 
O Topobo é composto de 10 dez blocos primitivos básicos os quais se conectam em diversas orientações. Nove destas primitivas são chamadas "passivas", pois formam ligações estáticas, sendo que 4 das formas geométricas ocorrem em duas escalas. A décima primitiva denominada "ativa", é um circuito eletrônico envolvido por uma capa plástica cuja constituição é de um motor associado a componentes eletrônicos constituindo uma tecnologia embarcada. Quando estas peças são unidas, cria uma rede peer-to-peer descentralizada.

Além dos componentes passivos com função meramente estrutural, o Topobo apresenta o conceito de memória cinética associada aos componentes ativos, a qual, por meio de um botão liga/desliga, permite que a manipulação de tais juntas possa ser registrada. O usuário pode programar manualmente a movimentação de uma junta através do uso da movimentação desse tipo de junta, que armazenará o movimento realizado.

Outra tecnologia disponível para a manipulação dos elementos é um tipo especial de dispositivo denominado Queens. Este permite que o sistema replique a outras juntas de peças ativas o movimento realizado, transmitindo a estas o mesmo movimento executado na queen.

$\mathrm{Na}$ figura 2 é mostrada a forma de programação de uma peça ativa que possui uma estrutura simples passiva, conectada na saída do motor.

\begin{tabular}{|c|c|c|c|}
\hline Conecta a energia & $\begin{array}{c}\text { Pressiona o botão } \\
\text { para gravar }\end{array}$ & $\begin{array}{c}\text { Alterar o } \\
\text { movimento do eixo }\end{array}$ & $\begin{array}{c}\text { Pressione o botão } \\
\text { novamente para } \\
\text { reproduzir o } \\
\text { movimento }\end{array}$ \\
\hline
\end{tabular}

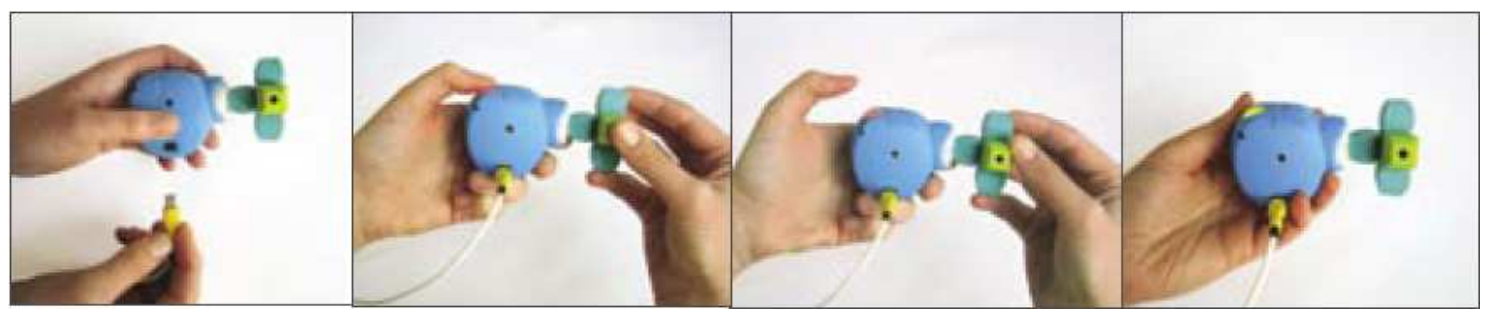

Figura 2: Programação tátil do Topobo

Um Topobo ativo é programado por manipulação direta, onde cada ativo sincroniza os registros por ele mesmo. Para registrar um movimento, um usuário pressiona o botão em um ativo, torce as peças ativas e produz um movimento na criação, desta forma realizando uma programação na forma de uma sequência de comportamentos. Ao pressionar o botão novamente, a criação imediatamente entra no modo de reprodução. Neste modo, reproduz o movimento várias vezes até que o botão é pressionado pela terceira vez para fazer com que o programa termine.

Apoiando a aplicação da tecnologia digital na educação, as interfaces ${ }^{1}$ digitais

\footnotetext{
${ }^{1}$ A interface informática designa um conjunto de aparelhos e materiais que possibilitam a comunicação entre um sistema informático e os humanos (Lévy, 1993).
} 
favorecem a ação autônoma e investigativa do aluno sobre o material educacional digital $^{2}$. Além disso, vão ao encontro do perfil da atual geração digital ${ }^{3}$ (Torrezan, 2009). Porém, devido à sua intimidade com a tecnologia digital, as interfaces consideradas tradicionais ou convencionais parecem afetar cada vez menos os nativos digitais (Veen e Vrakking, 2009).

O professor deve propor situações problemáticas que desafiem os alunos a resolvê-las com respostas buscadas em sua bagagem cultural e principalmente, no ato de suas ações. O diálogo, a discussão, como manifestação do ser humano dá-se em duas dimensões: "ação e reflexão" (Freire, 1987). A forma como o aluno interage com o Topobo, permite o conjunto ação e reação, pois o aluno tem uma resposta direta do equipamento. Asssim, o Topobo é uma ferramenta passível de aplicação em séries inicias, com crianças pequenas, utilizando noções de lógica de programação, pois é facultado ao Topobo uma programação de alto nível. Ele simplesmente responde a um estímulo mecânico da programação através do movimento das mãos sobre as peças. Segundo Hodson (1988), qualquer método didático que faça com que o aprendiz seja ativo, mais do que passivo, está de acordo com a ideia de que os alunos aprendem melhor pela experiência direta.

Aqui cabe ressaltar que a criança necessita ter uma habilidade mínima tátil que é segurar, para conseguir manipular os objetos sendo isto uma característica necessária para a manipulação da ferramenta.

A evolução da atividade lúdica está intimamente relacionada com todo o desenvolvimento da criança. Da evolução da utilização do brinquedo só se pode falar depois de se terem formado as coordenações sensório-motoras fundamentais que oferecem a possibilidade de manipular e atuar com os objetos. Sem saber sustentar um objeto na mão é impossível qualquer ação com ele, incluindo a lúdica. A primeira metade do primeiro ano de vida transcorre integralmente com uma formação adiantada dos sistemas sensoriais (Elkonin, 1998).

\section{Proposta metodologia para o uso do arcabouço}

Nesta seção é demostrada uma metodologia para auxiliar o professor a trabalhar com robótica educacional, em sala de aula.

Segundo Piaget (1971) o desenvolvimento das crianças entre os 2 e 7 anos, em geral, denomina-se período pré-operacional. Neste período há o desenvolvimento da linguagem, que trás três consequências para a vida mental que são: a socialização da ação, com trocas entre os indivíduos; o desenvolvimento do pensamento, a partir do pensamento verbal; e o desenvolvimento da intuição. Neste contexto, a proposta de se desenvolver conteúdos de ensino dar-se-á a partir do kit Topobo, permitindo explorar os conceitos de Robótica Educacional nesta faixa etária.

\footnotetext{
2 Material educacional digital (MED) é conceituado por esta pesquisa como sendo todo o material voltado à aprendizagem e que utiliza um ou mais recursos digitais na sua elaboração.

3 O termo "geração digital" reporta às pessoas que nasceram a partir de 1980 e que cresceram numa sociedade fortemente apoiada pelas tecnologias digitais (Veen e Vrakking, 2009).
} 
Estimular o desenvolvimento do processo criativo através da Robótica Educacional pode ser atingido a partir das seguintes atividades, propostas por Lopes (2008):

I) Design: desenho ou esboço apontando em termos gerais a ideia do projeto, como funciona e as partes.

II) Pesquisa: planejamento do projeto, apontando questões ou problemas, caminhos e soluções possíveis com base na pesquisa de modelos reais, de manuais ou de referência dos próprios sujeitos. protótipo.

III) Implementação: coleção das partes, montagem e primeiros testes do

IV) Programação: elaboração do software que controlará o protótipo.

$V)$ Depuração: aperfeiçoamento e correção de problemas.

VI) Registro: relatórios de atividades, registrando o processo de desenvolvimento do projeto, e relatório final.

Pela característica do kit Topobo avalia-se que a proposta é utilizar a metodologia de (BRAZ, 2010) para o desenvolvimento da robótica educacional com as crianças de séries iniciais. A proposta contempla 6 etapas detalhadas abaixo.

$1^{a}$ Etapa - Croqui Virtual. Com base na metodologia de projetos de aprendizado, esta etapa tem como objetivo despertar nos aprendizes a curiosidade, os interesses, as dúvidas associadas ao tema escolhido. Tais certezas e inquietações deverão ser traduzidas em um desenho - croqui. O croqui será realizado individualmente por cada educando, representando suas ideias e convicções associadas ao projeto a ser desenvolvido Desta forma, o design é o primeiro passo para criação, pois viabiliza a concretização das ideias imaginadas.

$2^{\text {a }}$ Etapa - Croqui Funcional. Dos estudos de Lopes (2008), ressalta-se que, ao desenhar seus protótipos, os sujeitos não apresentam todos os elementos mecânicos e lógicos articulados. É comum que partam da reprodução de um modelo real, onde apenas poucos elementos são destacados. É raro, nos desenhos, aparecerem elementos como motores, engrenagens, etc.

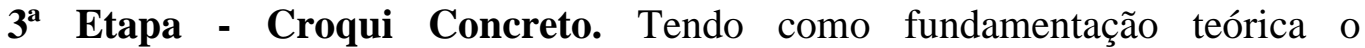
construcionismo de Papert (1993) esta fase baseia-se na construção do conhecimento através de uma ação concreta. Neste panorama, o processo de ensino-aprendizado vai além da aprendizagem formal, oportunizando atividades que provoquem o aluno a solucionar problemas, projetar e pensar suas ações.

$4^{\text {a }}$ etapa - Protótipo (montagem e construção). A soma das habilidades desenvolvidas nas etapas anteriores culmina nesta etapa. A equipe coloca em prática seu projeto, fazendo os testes e as adaptações necessárias para alcançarem seus objetivos. A preparação dos protótipos é realizada por todos os integrantes, sendo que estes devem seguir as orientações pensadas nas etapas anteriores. Ajustar o seu robô conforme o material disponível, tanto pensando na montagem como na programação, muitas vezes, nesta fase final, ainda exige da equipe buscar soluções criativas para problemas não previstos nos croquis.

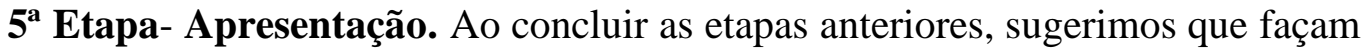
um relatório para fins de conduzir a equipe para apresentação, na qual será mostrado o sistema robótico construído, bem como o processo evolutivo do projeto, destacando os 
pontos fortes ou fracos do processo.

A figura 3. mostra as cinco fases para a qual se propõe na metodologia de utilização do kit Topobo.

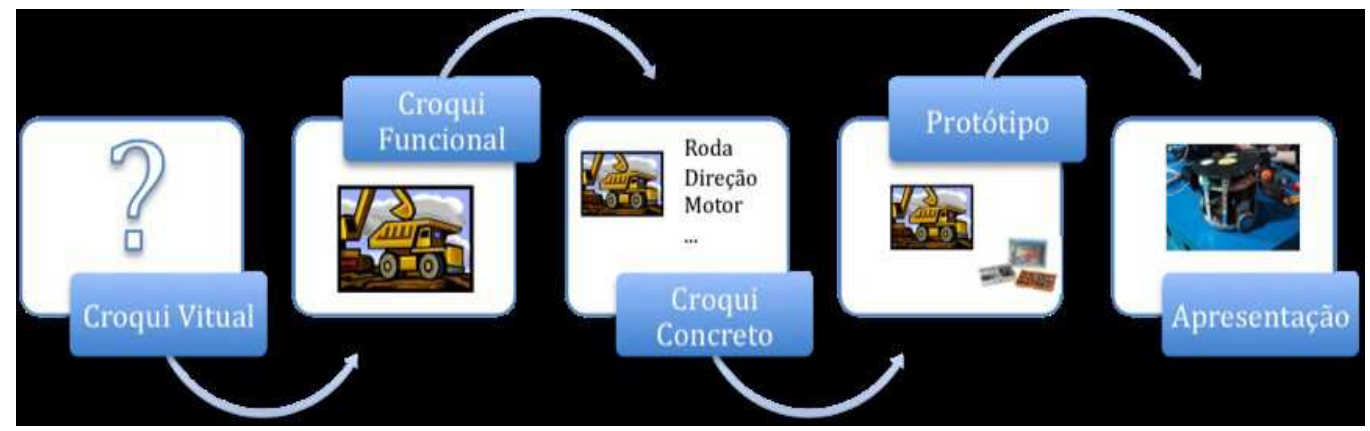

Figura 3: Etapas metodológicas de trabalho com Robótica Educacional

\section{Discussão da ferramenta e da metodologia em um contexto crítico}

Nesta seção será mostrado algumas percepções do uso de um kit Topobo comercial de 100 peças em um ambiente de pós-graduação em educação, onde a metodologia apresentada na seção anterior foi executada em um período de 40 minutos "simulando" o tempo de uma aula.

Segundo Behar (2009), a educação vive um momento de transformação, e os paradigmas presentes na sociedade não estão sendo suficientes para dar conta das relações, necessidades e desafios sociais. Conforme a autora, o modelo educativo atual privilegia o ensino tecnicista, que tem por objetivo preparar os indivíduos para desempenhar papéis específicos.

De posse de um kit Topobo comercial de 100 peças, o qual foi apresentado a um grupo de alunos em nível de mestrado e doutorado. O tempo de apresentação do kit foi de aproximadamente 40 minutos. $O$ trabalho se desenvolveu através de uma adaptação da proposta metodológica descrita na seção anterior, porém, separamos a turma em 3 grupos, destes, dois grupos com 4 componentes e um grupo com 5 alunos.

Fez-se a proposta para que cada um dos grupos desenvolvesse de forma livre um protótipo de animal ou veículo que pudesse deslocar-se a uma distância qualquer, e que justificassem como ele se movimentaria. Então, o grupo iniciou a interagir, cada um dando sua sugestão de como deveria ser o movimento para fazer o deslocamento. Pôdese observar que diversos conceitos de física e matemática apareceram de forma espontânea no grupo quando eles discutiram a tarefa.

O apresentador, professor, movia-se pela sala interagindo com os grupos e levantando propostas ou indagando as ideias do grupo, fomentando o diálogo em torno das propostas e das ideias que iam surgindo conforme eles se envolviam no assunto.

Após um tempo de discussão foi solicitado que o grupo desenhasse de forma livre o animal, ou veículo que cumprisse a tarefa inicial proposta.

Um dos grupos propôs um humanoide embora não estivesse na proposta inicial, optou-se por não descartar a ideia, pois se tinha como objetivo deixar fluir as discussões entre os alunos, neste momento os grupos passaram a interagir, pois quando alguém via o desenho do outro grupo voltava-se para os membros do seu grupo e comentavam a respeito.

Os grupos apresentaram os seus croquis. E com base nestes, conduziu-se uma 
discussão a respeito das funcionalidades, focando basicamente se a proposta desenhada conseguiria ser implementada e se ela atingiria o objetivo. Os grupos polemizaram que o humanoide não se sustentaria ao iniciar a andar, outro grupo propôs uma espécie de veículo. Neste momento, o professor informa que não existe rodas para implementação; alguns afirmaram que era impossível fazer sem as rodas. Então, volta à discussão sobre o humanoide, a construção e desconstrução das ideias do grupo são contínuas.

Partiu-se para a apresentação das peças disponíveis e foi solicitado que a partir destas, os grupos remodelassem seus protótipos.

Os grupos defenderam seus projetos e, elegeram um deles para que se realizasse a montagem e construção. O critério para eleição foi a facilidade para montagem com as peças disponíveis no kit e a chance da proposta de concluir a tarefa de forma mais rápida. Percebeu-se que a participação dos grupos foi um dos fatores que mais chamou a atenção, sendo que a dinâmica das atividades mostrou-se satisfatória e despertou o interesse dos participantes.

A utilização do Topobo de forma lúdica, juntamente com a dinâmica apresentada, mostrou-se como uma opção para auxiliar professores a desenvolver conteúdos de uma forma não tradicional.

\section{Considerações Finais}

Ao contrário de outras ciências, como a matemática e a biologia, por exemplo, a Computação é apresentada ao aprendiz tardiamente. Permitir que as crianças pensem autonomamente, desenvolvam sua criatividade e exerçam atividades cognitivas aptas à suas possibilidades é possível através do desenvolvimento do pensamento lógico.

Entretanto desenvolver o pensamento lógico em crianças é demasiadamente complexo pois exige um nível de abstração o qual elas não têm acesso, pois empregam um formalismo para se comunicar com a máquina, seja ele através de linguagens de programação as quais já empregam um nível de abstração cada vez menor, porém ainda demasiado alto para se empregar com crianças. Utilizar as mãos com artefatos que remetam a um estado de brincar pode ser a solução para enfrentar o alto nível de complexidade em construir programas.

As linguagens de programação exigem pensamentos que são muito distantes dos modos de pensar possíveis para a criança. Então fomentar o pensamento lógico da criança em uma ação mais próxima do seu mundo como a brincadeira e com o auxílio de artefatos educacionais os quais permitem investigar como elas organizam $o$ pensamento de forma lógica pode ser uma alternativa.

O Topobo como mostrado é um destes artefatos que reúne um conceito de programação manual e expõe a criança a organizar o pensamento de forma lógica.

Trabalhar ciência da computação desde cedo com as crianças permite o desenvolvimento do pensamento e a leitura do mundo integrados com uma cultura informatizada e digital que estamos vivenciando. Nossa sociedade integra ao cotidiano cada vez mais artefatos tecnológicos passando a sua utilização, tornarem-se fatos corriqueiros, exigindo dos sujeitos habilidades e conhecimento de informática para manipula-los. Garantir o acesso da criança a recursos de computação permitirá que ela integre um mundo contemporâneo e usufrua dos benefícios tecnológicos que são socialmente compartilhados. 


\section{Referências bibliográficas}

BEHAR, P. A. Modelos Pedagógicos em Educação a Distância. Porto Alegre: Artmed, 2009.

BITTERNCOURT, G. R. FERREIRA.M. D. M. A Importância do lúdico na alfabetização. Belém Pará, Universidade da Amazônia, 2002.

http://homolog.scielo.br/cgi-

bin/wxis.exe/iah/?IsisScript=iah/iah.xis\&base=article\%5edlibrary\&format=iso.pft\&lang $=\mathrm{p} \&$ nextAction $=\operatorname{lnk} \&$ index Search=AU\&exprSearch=BOMTEMPO,+EDDA

BOMTEMPO, E. Brinquedo e educação: na escola e no lar. Psicol. Esc. Educ. (Impr.) [online]. 1999, vol.3, n.1, pp. 61-69. ISSN 1413-8557.

BRAZ, L. G. Potencialiando a criatividade e a socialização: Um arcabouço para o uso da robótica educacional em direntes realidades educacionais. 2010. 118p. Dissertação ( Mestrado em Educação e Ciências) - Universidade Federal do Rio Grande - FURG. Rio Grand, 2010.

ELKONIN, D. B. Psicologia do jogo. São Paulo, SP: Martins Fontes, 1998.

FREIRE, P. 1987. Pedagogia do Oprimido. $17^{\text {a }}$ ed. Rio de Janeiro, Paz e Terra.

FURLANI, L. M. T. A claridade da noite: os alunos do ensino superior noturno. São Paulo: Cortez, 1998.

HODSON, D. Experimentos na Ciência e no ensino de Ciências. Educational Philosphy and Theory. Tradução de Paulo A. Porto, 20, p. 53-66, 1988.

LOPES, D. Q. A exploração de modelos e os níveis de abstração nas construções criativas com robótica educacional. 2008. 326f. Tese (Doutor em Informática na Educação) - Universidade Federal do Rio Grande do Sul- URGS, Porto Alegre, 2008.

PAPERT, S. Computadores e Conhecimento: repensando a educação. Campinas: Unicamp,1993.

PIAGET, J. A epistemologia genética. Trad. Nathanael C. Caixeira. Petrópolis: Vozes, 1971. 110p.

PIAGET, J. A formação do símbolo na criança: imitação, jogo e sonho, imagem e representação. Trad. Alvaro Cabral. Rio de Janeiro: Zahar, 1971. 
SARACHO, O. N. (1991). Educational play in early childhool education. Early Child Development and Care, vol. 66, 45-64.

TORREZAN, C. A. W.; R, E. B.; BEHAR P. A.; COSTA, P. A. A atuação das interfaces não-convencionáis na educação. RENOTE - Revista Novas Tecnologias na Educação, v.9, n.1,2010.

VEEN, W., VRAKKING, B. Homo Zappiens: educando na era digital. Porto Alegre:

Artmed, 2009.

VYGOTSKY, L. S. Play and its role in the mental development of the child. Soviet Psychology. 5, - 18, 1967. 